\title{
Analysis of wind resistance of high-rise building structures based on computational fluid dynamics simulation technology
}

\author{
Chunming Liu, Liang Liu*, Chengbin Liu \\ Department of Hydraulic and Architectural Engineering, Beijing Vocational College of Agriculture, Beijing 102442, China
}

Corresponding Author Email: 70808@bvca.edu.cn

https://doi.org/10.18280/ijht.360150

Received: 10 September 2017

Accepted: 22 December 2017

\section{Keywords:}

high-rise buildings, structural wind resistance, computational fluid dynamics, wind tunnel test, numerical simulation.

\begin{abstract}
This study focuses on wind resistance of high-rise building structures. Firstly, the monitoring results of wind tunnel test are compared with the numerical simulation results based on CFD to verify the feasibility of the CFD numerical method, and the wind pressure coefficients of full-size structures and multi-type high-rise buildings are analyzed with the CFD algorithm. The results show that the monitoring results based on wind tunnel test and CFD simulation are very similar, and the distribution of the overall wind pressure coefficients is basically the same. As seen in top view and elevation view of wind pressure coefficient contours for full-size building structures, the wind pressure coefficient on the windward side and leeward side of a full-size building is relatively small, and the wind pressure coefficient in the incoming wind side is relatively large, which is because of the influence of Reynolds Number Effect in the area of the incoming wind side, which results in the relatively greater negative pressure on the lateral side of the building. The contour distribution of wind pressure coefficients for different types of buildings is generally similar, indicating that the shape of buildings has basically no effect on the distribution of wind pressure coefficients. This study establishes static pressure field fitting curves for the windward, crosswind, upwind, and leeward directions. The "static pressure corridor" can accurately determine the zero pressure position, and long-term monitoring at the point with zero pressure can achieve the best test results.
\end{abstract}

\section{INTRODUCTION}

According to statistics, (super) high-rise buildings in coastal areas are affected by typhoons for 7-12 times a year. The natural vibration frequency of (super) high-rise buildings is similar to the main frequency rate of typhoon pulsating loads, and the response of high-rise buildings to typhoon is strong. The structural disturbance of (super) high-rise buildings under wind load has been the focus and difficulty of researches in recent years [1-4].

Field monitoring is the best way to test the wind resistance of building structure, but the high test cost and site environment cause many difficulties in field monitoring [5-9]. Most researchers use pneumatic tests and numerical simulation based on computational fluid dynamics (CFD) to analyze the wind resistance performance of the structures [1013]. In the wind tunnel test, a wind tunnel flow field is built in a laboratory, with high-rise buildings reduced in equal proportion (similar simulation test), then the response of the high-rise building to wind disturbance can be studied from various angles and in various conditions. At present, the research direction mainly focuses on wind pressure distribution on building surface, wind load amplitude characteristics, static pressure field distribution, etc. [14-17]. However, the similar simulation tests require strict conditions for scaling with equal proportion. It is difficult to restore the situation in the test results and there are errors in the results obtained. The numerical simulation based on CFD has the advantages of low cost and repeatable calculation, and is the most frequently used research method at present [18-20].
The study focuses on wind resistance of high-rise buildings. Firstly, the monitoring results of wind tunnel test are compared with the numerical simulation results based on CFD to verify the feasibility of the CFD numerical method, and the CFD algorithm is used to analyze the wind pressure coefficients of full- size structures and multi-type high-rise buildings. The research conclusions can provide a new idea for the research on wind resistance of high-rise buildings [21].

\section{WIND TUNNEL TEST AND CFD SIMULATION ANALYSIS}

\subsection{Brief introduction of wind tunnel test}

The size of the wind tunnel laboratory is $23 \mathrm{~m} * 6 \mathrm{~m} * 3 \mathrm{~m}$, with complete test equipment. The models are scaled down by $1: 150$. The range of test wind speed is $0-25 \mathrm{~m} / \mathrm{s}$ and the ground roughness is $\alpha=0.12$. Figure 1 shows the average wind speed and turbulence curves of wind field in A-type geomorphology.

Figure 2 shows the layout of totally 22 measuring points on the 30th floor of the building. The test incoming wind angle is as shown in Figure 3, with a frequency of $400 \mathrm{~Hz}$ and a sampling length of 5,000 data.

Formula 1 is used to calculate the wind pressure coefficient $\mathrm{C}_{\mathrm{p}}$ at a certain point of a building:

$C_{p}=\frac{p-p_{s}}{0.5 \rho v_{s}^{2}}$ 
where, $p_{s}$ is the static pressure at a certain point of the original wind tunnel, and $\mathrm{p}$ is the static pressure at that point after construction. $\rho$ and $\mathrm{v}$ are air density and wind speed, respectively.

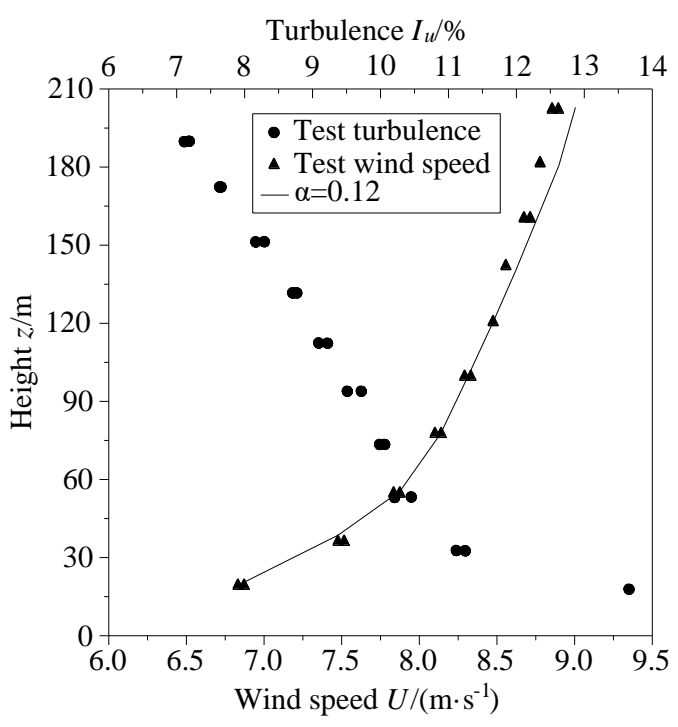

Figure 1. The average wind speed and turbulence curve of the wind field

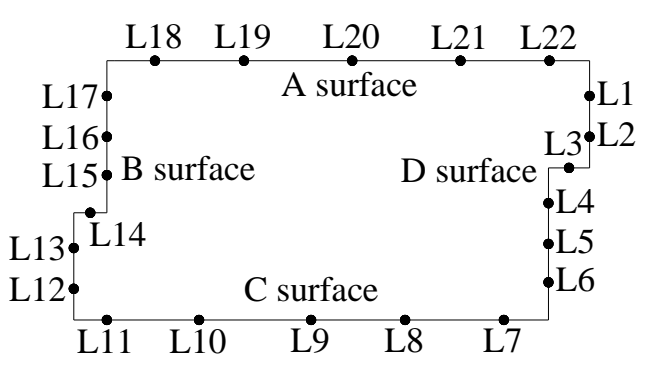

Figure 2. Measuring point layout

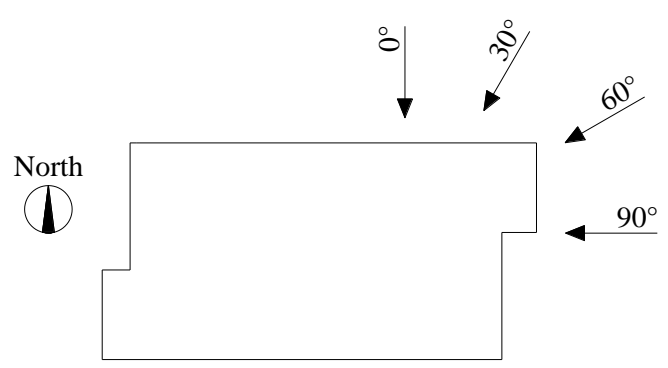

Figure 3. Angle of incoming wind in the experiment

\subsection{CFD numerical modeling}

Fluent software is used for numerical modeling based on fluid mechanics, with the same size of the model and the wind tunnel laboratory as those in the wind tunnel test. The network of the building and its adjacent area are encrypted, with a model of Realizable k- $\varepsilon$. The calculation program is a threedimensional single-precision solver, and the flow field uses the SIMPLEC algorithm.

\subsection{Comparative analysis of the results of the two methods}

Figures 4 and 5 show the wind tunnel test points and the wind pressure coefficient of 22 measuring points based on CFD numerical simulation when the incoming wind angle is $0-90^{\circ} \mathrm{C}$. As it can be seen from the comparison of the two figures, the monitoring results based on wind tunnel test and CFD simulation are very similar, and the overall distribution of wind pressure coefficients is basically the same, suggesting that it is feasible to use CFD simulation to analyze the windresistance response and static pressure field distribution of high-rise buildings.

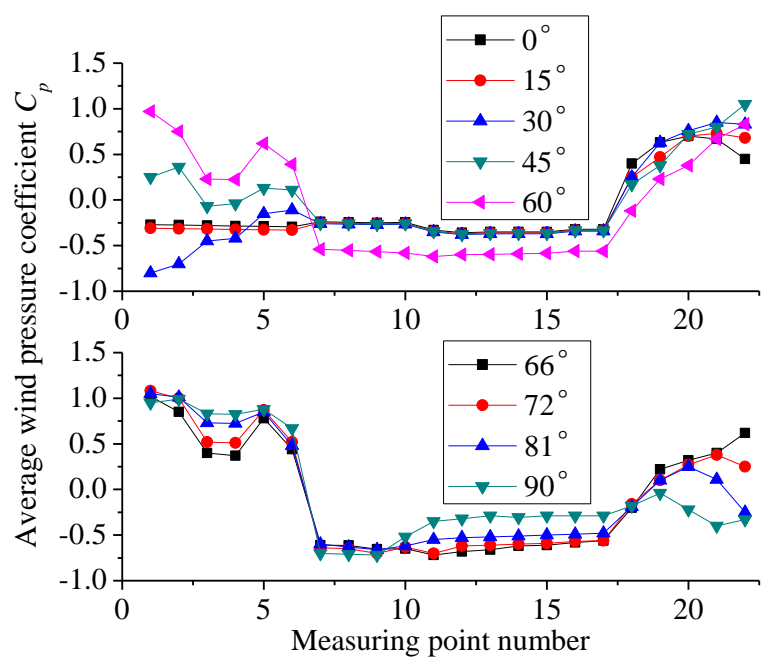

Figure 4. Wind pressure coefficients of wind tunnel test points at different incoming wind angles

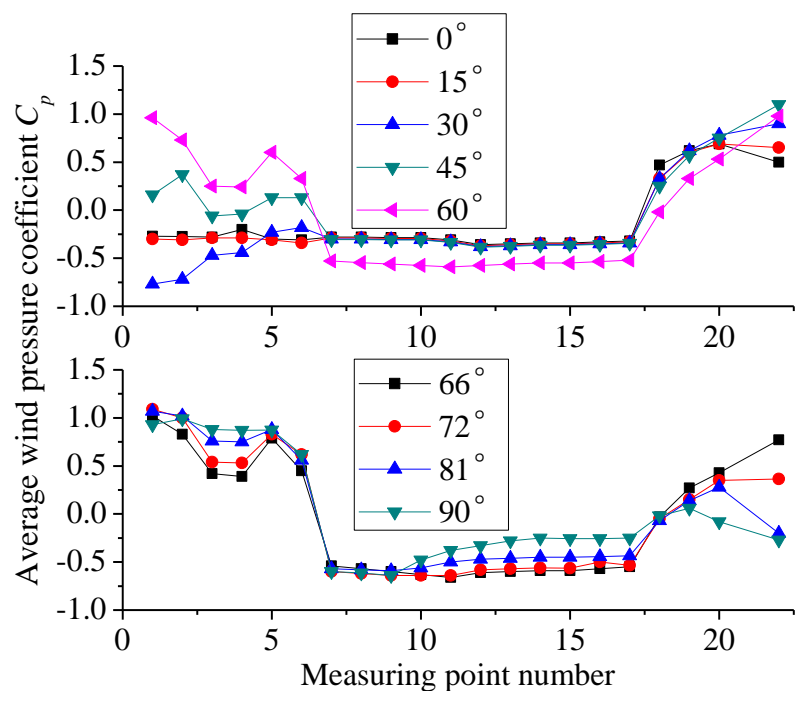

Figure 5. Wind pressure coefficient of each CFD simulation measuring point at different incoming wind angles

\section{ANALYSIS ON WIND RESISTANCE OF MULTI- TYPE HIGH-RISE BUILDING STRUCTURES BASED ON CFD NUMERICAL SIMULATION}

\subsection{Calculation of wind pressure coefficients of full-size structures}

Relevant studies have shown that the wind pressure test results of the scaled model established by the wind tunnel test have some errors compared with the actual monitoring results. In this section, CFD numerical simulation is used to analyze the distribution of wind pressure coefficients and static 
pressure field around the full-size building structure. The relevant parameters are set as above.

Figure 6 shows top view and elevation view of wind pressure coefficient contours for full-size building structures. As can be seen in the figure, the wind pressure coefficients on the windward side and the leeward side of the building are relatively small, which is in line with the theory of fluid mechanics. As the number of buildings increases, the wind flow blocking effect in the wind tunnel gradually increases, which leads to the increase of the drag coefficient inside the wind tunnel. The wind pressure coefficient in the lateral area of the coming wind is relatively higher, since the area is affected by the Reynolds Number Effect, and the negative pressure on the building is relatively greater. As can be seen from Figure 6(b), the wind pressure around the building is distributed in a three-dimensional structure, and the wind pressure coefficient at the top of the building is more densely distributed and more greatly varied, so the measuring points should be as far away from the roof position as possible, so as to improve the testing accuracy. As can be seen from Figure 6, it is feasible to use CFD to simulate the wind-resistance response of full-size buildings, and the calculated results can better reflect the actual wind-resistance characteristics of buildings.

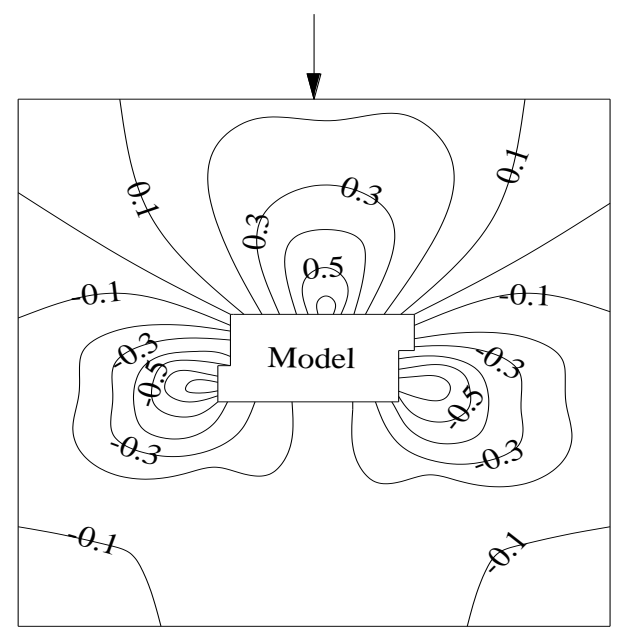

(a) Top view

0

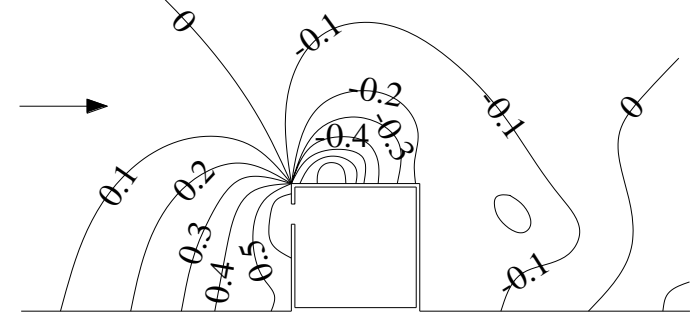

(b) Elevation view

Figure 6. Distribution of wind pressure coefficient contours of full-size building structures

\subsection{Analysis on wind resistance of multi-type high-rise building structures}

In order to further study the wind resistance of multi-type high-rise building structures, a circular building (diameter of $60 \mathrm{~m}$ and height of $70 \mathrm{~m})$ and a rectangular building $(32 \mathrm{~m} \times$
$15 \mathrm{~m} \times 100 \mathrm{~m})$ are established. Figure 7 shows the distribution of the wind pressure coefficient contours of circular and rectangular high-rise buildings. As can be comparatively seen from Figures 6 and 7, the distribution of the wind pressure coefficient contours of the three types are generally similar, indicating that the shape of the buildings basically has no influence on the wind pressure coefficients.

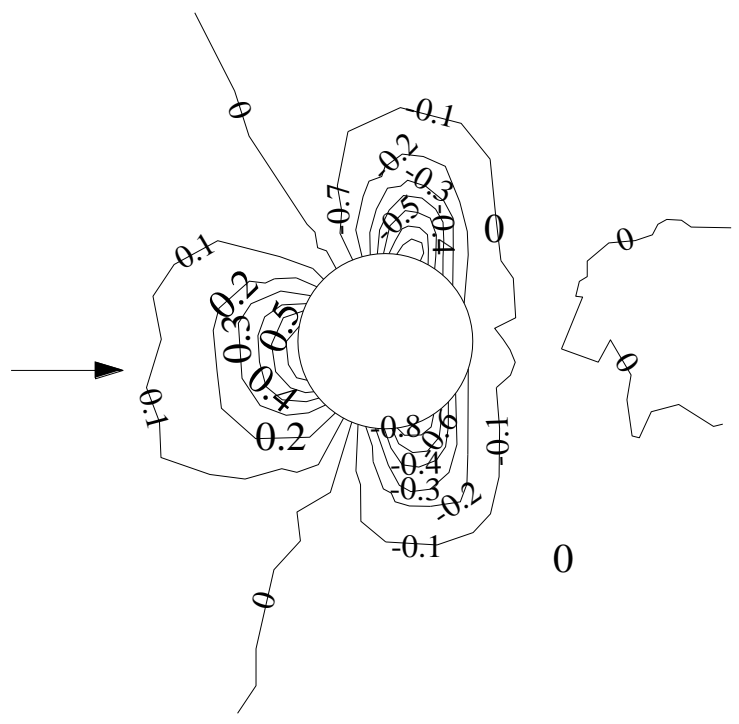

(a) The circular

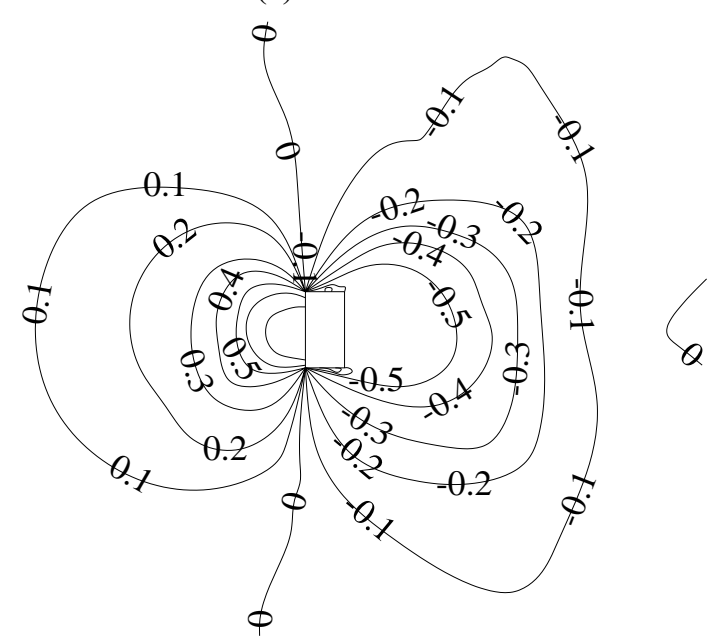

(b) The rectangular

Figure 7. Distribution of the wind pressure coefficient contours of circular and rectangular buildings

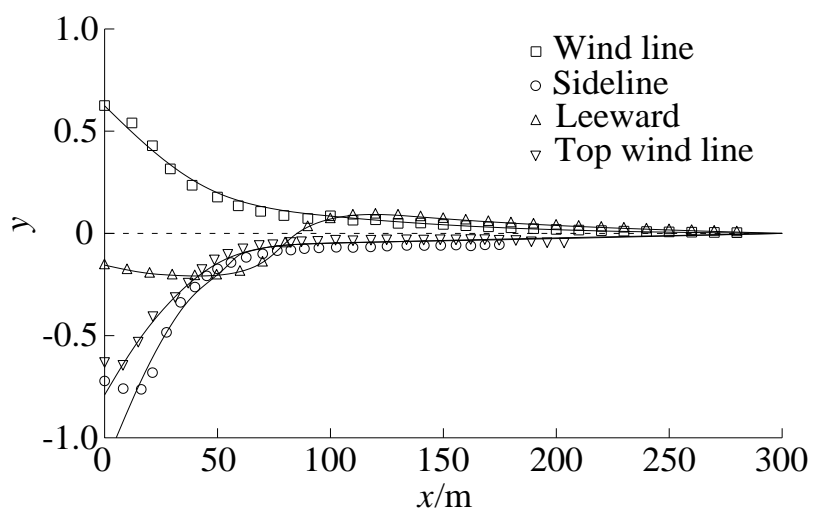

(a) Structure shown in Figure 6 


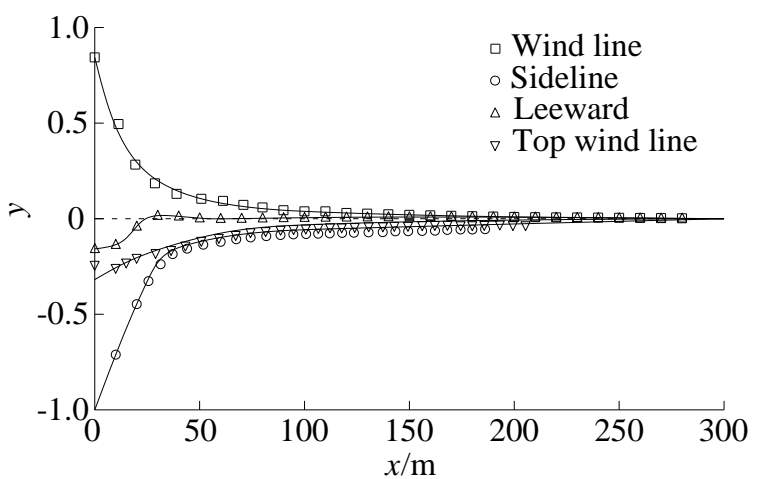

(b) The circular

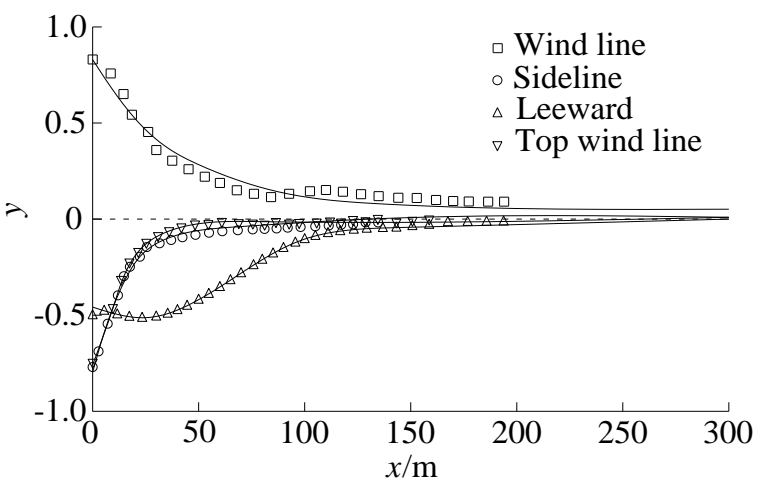

(c) The rectangular

Figure 8. Wind pressure fitting curves for different types of buildings

The wind pressure monitoring values of three types of buildings in four directions (windward, crosswind, leeward and upwind) are fitted, and the fitted curves are shown in Figure 8. The abscissa in the Figure is the distance from the building. According to the fitting conditions of the three buildings, the fitted curves in the three directions of windward, crosswind and upwind can be expressed as:

$$
y=k a^{(x+b)}
$$

The leeward fitted curve is expressed as

$$
y=\frac{a_{1}+a_{3} x+a_{5} x^{2}}{1+a_{2} x+a_{4} x^{2}}
$$

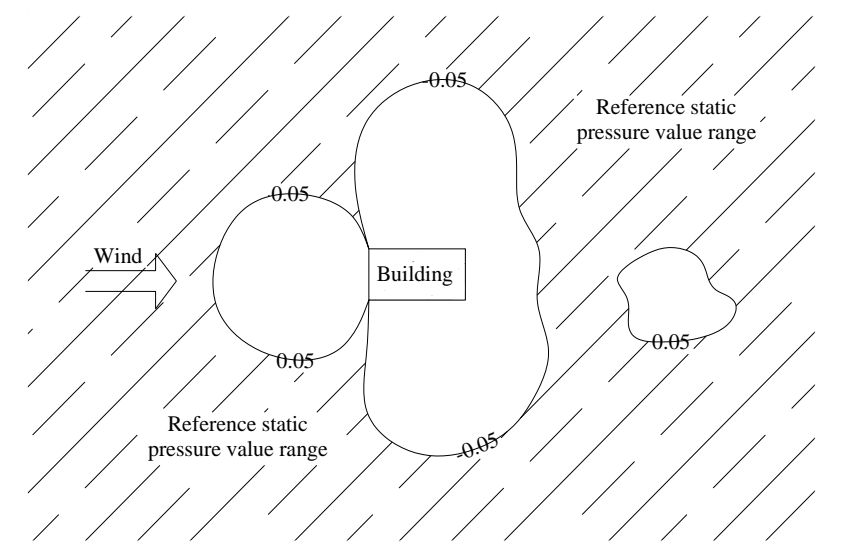

Figure 9. Static pressure field contour curves
Identification of static pressure field boundary is an important step for long-term monitoring of a building. Figure 9 shows the static pressure field determined with a wind pressure coefficient of 0.05 as a boundary, and the region, where the wind pressure coefficient is less than 0.05 , is represented by a shadow.

Take the circular building as an example to obtain the static pressure field. It can be seen from Figure 10 that the starting point of the static pressure field is located at the part of the structure with 0 pressure, the static pressure corridor is mainly distributed at 55-75 degrees, and long-term monitoring at the point with 0 pressure can achieve the best test results.

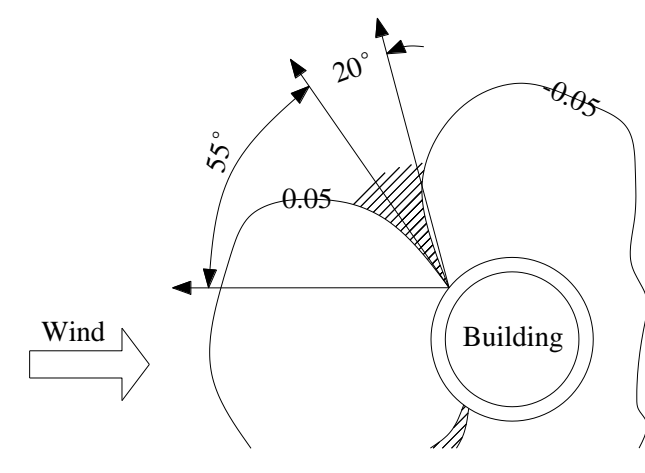

Figure 10. Static pressure corridor of the circular building

\section{CONCLUSIONS}

This study focuses on wind resistance of high-rise buildings. Firstly, the monitoring results of wind tunnel test are compared with the numerical simulation results based on CFD to verify the feasibility of the CFD numerical method, and the CFD algorithm is used to analyze the wind pressure coefficients of full- size structures and multi-type high-rise buildings. The results are as follows:

(1) The monitoring results based on wind tunnel test and CFD simulation is very similar, and the distribution of the overall wind pressure coefficients is basically the same. As seen in top view and elevation view of wind pressure coefficient contours for full-size building structures, the coefficient of wind pressure on the windward side and leeward side of a full-size building is relatively small, and the wind pressure coefficient in the lateral area of the incoming wind is relatively large, due to the influence of Reynolds Number Effect in the area and the relatively greater negative pressure on the lateral side of the building.

(2) The distribution of wind pressure coefficient contours for different types of buildings is generally similar, indicating that the shape of buildings has basically no effect on the distribution of wind pressure coefficients. This study establishes static pressure field fitting curves for the windward, crosswind, upwind, and leeward directions. The "static pressure corridor" can accurately determine the zero pressure position, and long-term monitoring at the point with zero pressure can achieve the best test results.

\section{REFERENCES}

[1] Badri AA, Hussein MM, Attia WA. (2015). Study of wind tunnel test results of high-rise buildings compared to different design codes. Wind \& Structures An 
International Journal 20(5):

$623-642$

https://doi.org/10.12989/was.2015.20.5.623

[2] Quan Y, Liang Y, Wang F, Gu M. (2011). Wind tunnel test study on the wind pressure coefficient of claddings of high-rise buildings. Frontiers of Architecture \& Civil Engineering in China 5(4): 518-524. https://doi.org/10.1007/s11709-011-0128-4

[3] Quan Y, Yan Z, Wen C, Fang H, Gu M. (2011). Wind tunnel test study on local wind pressure of rectangular super high-rise building with openings. Building Structure 41(4): 113-116.

[4] Jiang J, Hao J. (2011). Wind tunnel test study on rigid model of a super high-rise building. International Conference on Remote Sensing, Environment and Transportation Engineering 1884-1887. IEEE. https://doi.org/10.1109/rsete.2011.5964666

[5] Shi WH, Li ZN. (2011). Field measurement of boundary layer wind characteristics and wind loads on super-tall building. Advanced Materials Research 243-249: 51285135 .

https://doi.org/10.4028/www.scientific.net/amr.243249.5128

[6] Zhi LH, Jiang SY, Lu CL. (2014). Study on wind load characteristics of a super tall building based on numerical simulation. Applied Mechanics \& Materials 578-579: 810-813.

https://doi.org/10.4028/www.scientific.net/amm.578579.810

[7] Lam KM, Li A. (2009). Mode shape correction for windinduced dynamic responses of tall buildings using timedomain computation and wind tunnel tests. Journal of Sound \& Vibration 322(4-5): 740-755. https://doi.org/10.1016/j.jsv.2008.11.049

[8] Ke S, Wang H, Ge Y. (2016). Wind load effects and equivalent static wind loads of three-tower connected tall buildings based on wind tunnel tests. Structural Engineering \& Mechanics 58(6): 967-988. https://doi.org/10.12989/sem.2016.58.6.967

[9] Fu JY, Li QS, Wu JR, Xiao YQ, Song LL. (2008). Field measurements of boundary layer wind characteristics and wind-induced responses of super-tall buildings. Journal of Wind Engineering \& Industrial Aerodynamics 96(8): 1332-1358. https://doi.org/10.1016/j.jweia.2008.03.004

[10] Ramponi R, Blocken B. (2012). Cfd simulation of crossventilation flow for different isolated building configurations: validation with wind tunnel measurements and analysis of physical and numerical diffusion effects. Journal of Wind Engineering \& Industrial Aerodynamics s104-106(3): 408-418. https://doi.org/10.1016/j.jweia.2012.02.005

[11] Huang L, Chang L. (2012). Study on wind-resistant design for super high-rise building envelop. Advanced Materials Research 368-373: 2089-2093. https://doi.org/10.4028/www.scientific.net/amr.368373.2089

[12] Sivakumar K, Rajan K. (2015). Experimental analysis of heat transfer enhancement in a circular tube with different twist ratio of twisted tape inserts, International Journal of Heat and Technology 33(3): 158-162. https://doi.org/10.18280/ijht.330324

[13] Perrone D, Amelio M. (2016). Numerical simulation of MILD (moderate or intense low-oxygen dilution) combustion of coal in a furnace with different coal gun positions, International Journal of Heat and Technology 34(S2):

S242-S248. https://doi.org/10.18280/ijht.34Sp0208

[14] Li Y, Li QS, Ju KL. (2013). Experimental investigation of the wind pressure distribution and wind interference effects on a typical tall building. Advanced Materials Research 639-640(2): 444-451. https://doi.org/10.4028/www.scientific.net/amr.639640.444

[15] Gu M, Xie ZN. (2011). Interference effects of two and three super-tall buildings under wind action. Acta Mechanica Sinica 27(5): 687-696. https://doi.org/10.1007/s10409-011-0498-9

[16] Kim W, Tamura Y, Yoshida A, Yi JH. (2017). Interference effects of an adjacent tall building with various sizes on local wind forces acting on a tall building. Advances in Structural Engineering, 136943321775017. https://doi.org/10.1177/1369433217750170

[17] Huang G, Chen X. (2007). Wind load effects and equivalent static wind loads of tall buildings based on synchronous pressure measurements. Engineering Structures 29(10): 2641-2653. https://doi.org/10.1016/j.engstruct.2007.01.011

[18] Xie Z, Shi B, Ni ZH. (2002). Wind pressure distribution on complex shape tall buildings under wind action with interference effects by a downwind building. Journal of Building Structures 23(4): 27-31.

[19] Wang J, Yang L, Xu ZZ, Zhong R, Wu GH, Zhang XX, Li XJ, Xie YH, Zhu T. (2016). Numerical simulation on underwater explosion in small-sized containers, Mathematical Modelling of Engineering Problems 3(3): 151-156. https://doi.org/10.18280/mmep.030307

[20] Zhang W, Du XZ, Yang LJ, Yang YP. (2016). Research on performance of finned tube bundles of indirect aircooled heat exchangers, Mathematical Modelling of Engineering Problems 3(1): 47-51. https://doi.org/10.18280/mmep.030108

[21] Yao Y, Geng WB. (2017). Study on flight control of multi - rotor plant protection unmanned aerial vehicle, Academic Journal of Manufacturing Engineering 15(2): 95-100. 